\title{
The Molecular and Biophysical Characterization of the Human Blood-Nerve Barrier: Current Concepts
}

\author{
Eroboghene E. Ubogu
}

Neuromuscular Immunopathology Research Laboratory, Department of Neurology, Baylor College of Medicine, Houston, Tex., USA

\author{
Key Words \\ Blood-nerve barrier $\cdot$ Humans $\cdot$ In vitro models $\cdot$ Leukocyte \\ trafficking $\cdot$ Microvascular repair $\cdot$ Mitogens $\cdot$ Peripheral \\ nerves $\cdot$ Solute permeability $\cdot$ Transendothelial electrical \\ resistance
}

\begin{abstract}
The internal microenvironment in peripheral nerves is highly regulated in order to maintain normal axonal impulse transmission to or from the central nervous system. In humans, this regulation is facilitated by specialized tight junction (TJ)-forming endoneurial microvascular endothelial cells and perineurial myofibroblasts that form multiple concentric layers around nerve fascicles. The endoneurial endothelial cells come in direct contact with circulating blood and, thus, can be considered the blood-nerve barrier (BNB). Studies on the molecular and biophysical properties of the human BNB in vivo or in situ are limited. Owing to the recent isolation of primary human endoneurial endothelial cells and the development of simian virus 40 large T-antigen immortalized cell lines, data are emerging on the structural and functional characteristics of these cells. These data aim to increase our understanding of how solutes, macromolecules, nutrients and hematogenous leukocytes gain access into or are restricted from the endoneurium of peripheral nerves. These concepts have clinical relevance in understanding normal peripheral nerve homeostasis, the response
\end{abstract}

of peripheral nerves to external insult and stresses such as drugs and toxins and the pathogenesis of peripheral neuropathies. This review discusses current knowledge in this nascent and exciting field of microvascular biology.

Copyright $\odot 2013$ S. Karger AG, Basel

\section{Introduction}

Peripheral nerves are responsible for impulse transmission from the periphery to the central nervous system (CNS) for processing and transmit output impulses from the CNS back to the periphery to facilitate effector functions such as locomotion. These impulses are generated and directed via the sequential process of axonal depolarization and subsequent repolarization, a process dependent on sodium and potassium channel flux. This process is crucial for normal human function, thus, the ionic gradients within peripheral nerves must be tightly regulated to prevent variations in sodium and potassium concentrations from altering signal transmission $[1,2]$. Furthermore, solutes and macromolecules that could influence the ionic balance within peripheral nerves require regulated control.

Human peripheral nerves have a multilayered structural organization with an anastomosis of blood vessels that supply these layers. Peripheral nerves are divided into an outermost epineurium, inner perineurium and inner-

\section{KARGER}

E-Mail karger@karger.com

www.karger.com/jvr
(C) 2013 S. Karger AG, Basel

1018-1172/13/0504-0289\$38.00/0
Dr. Eroboghene E. Ubogu

Department of Neurology, Baylor College of Medicine

One Baylor Plaza, NB 302

Houston, TX 77030-3411 (USA)

E-Mail ubogu@bcm.edu 

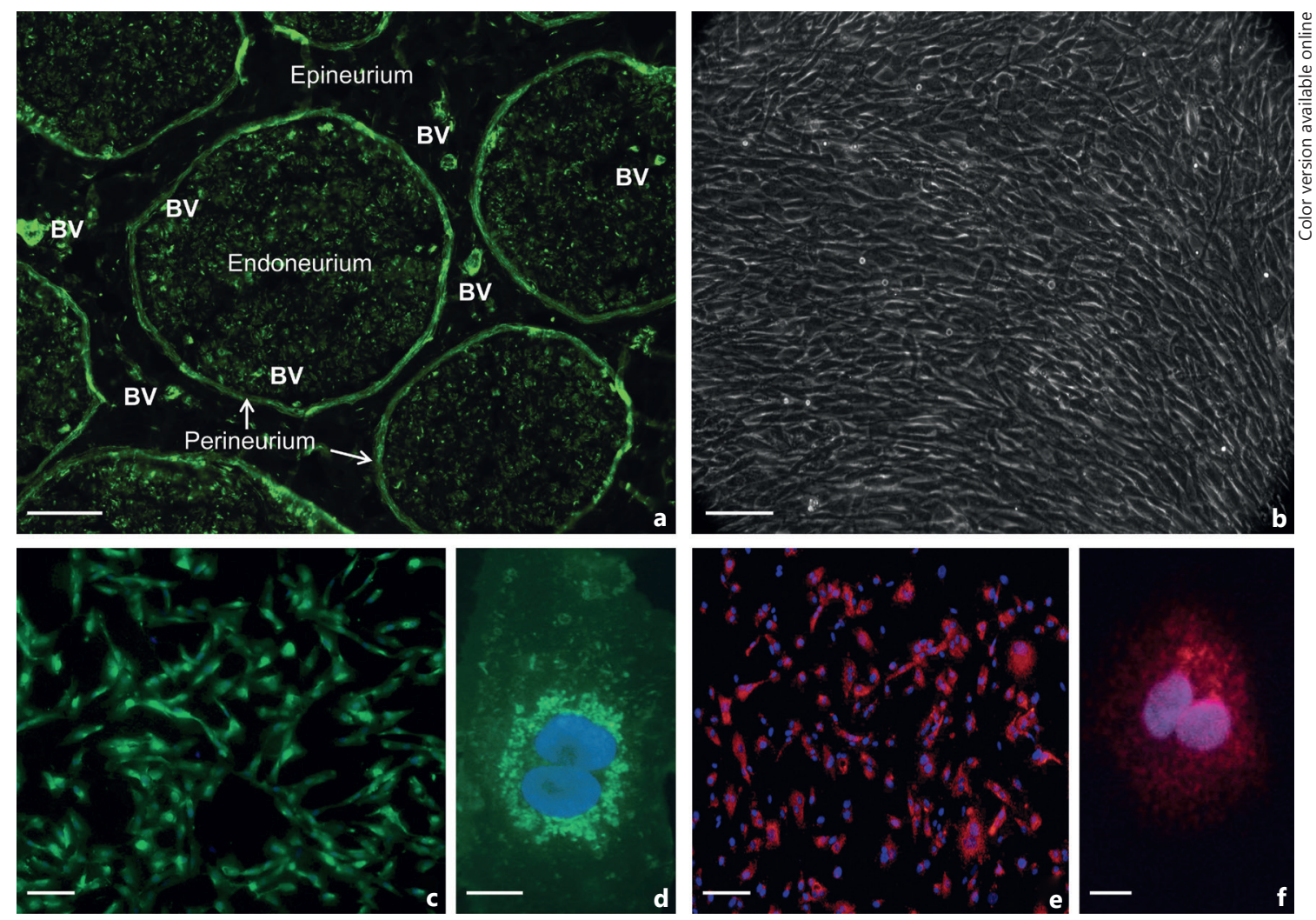

Fig. 1. Peripheral nerve anatomy and characteristics of primary endoneurial endothelial cells. A digital photomicrograph of an axial cryostat section of human sciatic nerve stained with fluoresceinated UEA-1 demonstrates the multilayered anatomical organization of peripheral nerves, with blood vessels (BV) within the epineurium and endoneurium indicated (a). A digital phase-contrast photomicrograph demonstrates confluent, spindle-shaped pHEndECs 6 days after being cultured on rat tail collagen-coated CellBIND ${ }^{\circledR}$ tissue culture plates at the onset of a flow-dependent leukocyte trafficking assay (b). Proliferating pHEndECs strongly bind UEA-1, as expected for human vascular endothelial cells (c) with more intense perinuclear staining seen at higher magnification (d), as shown by these direct immunocytochemistry digital photomicrographs of fixed cells cultured on rat tail collagen-coated glass coverslips. Intracellular von Willebrand factor expression, another marker of vascular endothelial cells, is demonstrated on fixed, permeabilized proliferating $\mathrm{pHEndEC}$ cultures grown on rat tail collagen-coated glass coverslips (e), with intracellular perinuclear expression verified at higher magnification (f), based on these digital indirect immunocytochemistry photomicrographs. Scale bars $=100(\mathbf{a}-\mathbf{c}, \mathbf{e})$ and $5 \mu \mathrm{m}(\mathbf{d}, \mathbf{f})$. most endoneurium (fig. 1a). The endoneurium is completely surrounded by the perineurium (forming a nerve fascicle), with several nerve fascicles embedded within the epineurium. The endoneurium is of critical importance to the primary function of peripheral nerves as it contains the axons and their supporting Schwann cells, which either myelinate segments of single axons or envelope clusters of small axons without myelination [1-4].

The vascular supply of peripheral nerves is derived from radial branches of nearby arteries, forming the vasa nervosum that runs in the longitudinal axis of the nerve in the outer epineurium. These vessels generate branches that transverse deeper into the epineurium, forming small arteries and arterioles, eventually resulting in precapillary arterioles that run on the external surface of the perineu- rium. These vessels subsequently produce branches that penetrate the concentric multilayered perineurium to enter the endoneurium, forming capillaries. These capillaries may drain into larger postcapillary venules within the endoneurium, with venules emerging through the perineurium. Venules and small veins run longitudinally within the epineurium, eventually joining to form the larger veins that drain the peripheral nerve into nearby veins via radial branches $[1,2,5]$.

Ultrastructural examination of the human peripheral nerve vascular supply demonstrates electron-dense rich intercellular tight junctions (TJs) between endothelial cells within the endoneurium, with small 50 - to $100-\mathrm{nm}$ intracellular pinocytic vesicles. These endothelial cells lack fenestrations. This is in contrast to endothelial cells 
within the epineurium and perineurium that contain numerous fenestrations and lack TJs [3, 4]. These observational data imply that endoneurial microvascular cells are specialized endothelial cells, similar to endothelial cells that form the restrictive blood-brain (BBB) and bloodtestis barriers. These ultrastructural studies also demonstrate intercellular TJs between adjacent perineurial myofibroblast cells, particularly within the inner concentric layers $[3,4]$. These observations indicate that specialized interfaces within peripheral nerves occur, with expected restrictive barrier-like properties.

The lack of TJs between macrovascular endothelial cells within the epineurium as well as the presence of fenestrations between these cells suggests that solutes, macromolecules and other blood-borne substances may 'leak' into the epineurium and constitute its interstitial fluid [6]. Due to the fact that the epineurium structurally consists of longitudinal arrays of collagen fibers (needed to maintain the structural integrity of the peripheral nerve), these substances can freely diffuse within this layer. Thus, the perineurium serves to protect the innermost layer of peripheral nerves, the endoneurium, from this passive diffusion of epineurial interstitial fluid components [1-4]. The specialized endoneurial microvascular endothelial cells come in direct contact with substances in circulating blood, and can be considered the blood-nerve barrier (BNB).

Compared to other microvascular endothelial cells, very little is known about human endoneurial endothelial cells (HEndECs). Understanding the biology of these endothelial cells can provide insights into how solutes and macromolecules gain access into or are expelled from the endoneurium, providing cues to the nutritional requirements of peripheral nerves and the mechanisms of regulated removal of metabolic end-products. Resident macrophages and mast cells are commonly observed in normal peripheral nerves. These cells could act as primary responders to endoneurial injury and participate in the innate immune response to foreign pathogens. Rare $\mathrm{T}$ cells may be seen in normal nerves, hypothesized to be involved in normal immune surveillance. However, recruitment of hematogenous monocytes and $\mathrm{T}$ cells is commonly seen following peripheral nerve injury or in immune-mediated peripheral neuropathies such as Guillain-Barré syndrome, implying that functional and structural modifications occur at the human BNB $[1,2]$. In situ observational studies in human and rodent peripheral nerves imply progressive BNB maturation during fetal and postnatal development $[7,8]$. Endoneurial endothelial cell proliferation and restoration of restrictive barrier function are intuitively expected during peripheral nerve

Human Blood-Nerve Barrier

Characterization recovery from injury $[9,10]$. It is important to know whether endogenous or exogenous mitogens participate in these processes and their cellular sources.

Knowledge of the human BNB had been limited for many years by difficulties in isolating and culturing endoneurial endothelial cells. Due to functional and phenotypic differences between microvascular endothelial cells from different tissues and species [11-13], this work requires HEndECs. Recent success within the last 4 years has resulted in the initial characterization of primary HEndECs (pHEndECs), also known as peripheral nerve microvascular endothelial cells (PnMECs), and the development of simian virus 40 large T antigen (SV40 LTA) immortalized cell lines, with emerging data on the molecular and biophysical characteristics of the human BNB in vitro, and responses to different substances under normal physiological and pathophysiological conditions [14-19].

\section{Molecular Characterization of HEndECs}

pHEndECs have been successfully isolated and purified from the sciatic nerves of recently decedent individuals. The sciatic nerve is the largest nerve in the human body and provides sufficient material to isolate endoneurial endothelial cells (constitute $<0.1 \%$ of the cellular components of peripheral nerves) using endoneurial stripping, enzymatic digestion and density gradient centrifugation. These cells have been successfully cultured and expanded for up to 10 passages in vitro, as well as immortalized via stable transfection with plasmids containing SV40 LTA, as well as retrovirus vectors containing temperature-sensitive SV40 LTA and telomerase [14-19]. When grown to confluence, these endothelial cells form the framework for in vitro models of the human $\mathrm{BNB}$ (fig. 1b). Immunocytochemistry, flow cytometry, polymerase chain reaction (PCR) and Western blot techniques have been employed to determine the molecular characteristics of these human BNB-forming primary and immortalized cell lines.

\section{Vascular Endothelial Cell Markers}

Primary and immortalized HEndECs bind Ulex europaeus agglutinin-1 (UEA-1), the most sensitive marker of vascular endothelial cells in vitro and in situ (fig. 1c, d). This indicates $\alpha$-L-fucose expression by the BNB-forming cells in vitro, as expected in vivo $[14,15,20]$. Furthermore, these cells intensely take up fluorescently labeled 
acetylated low-density lipoproteins, indicative of the expression of specialized scavenger receptors, as expected of microvascular endothelial cells $[14,15,17,19]$. von Willebrand factor (also known as factor VIII-related antigen), a large multimeric glycoprotein that is important for hemostasis and constitutively produced in intracellular Weibel-Palade bodies [21], is reliably expressed by pHEndECs $[14,17]$ (fig. 1e, f) with reported loss of expression in plasmid-transfected immortalized cells [15] and retained expression with retroviral transfected cells [19]. Loss of Weibel-Palade bodies has been described in immortalized human endothelial cell lines [22], implying that these cell lines may be less useful for studying mechanisms of hemostasis relevant to endoneurial microvascular repair in peripheral nerves.

\section{Growth Factor Ligands/Receptors}

pHEndECs reliably proliferate in vitro for at least 8 passages with a doubling of cell numbers every $48 \mathrm{~h}$ during the early logarithmic growth phase, followed by contact inhibition [14]. Immortalized endoneurial endothelial cells have been successfully expanded to 27 passages ( $>45$ population doublings and $>80$ days in continuous culture) with variable population doubling time from approximately 28 to $53 \mathrm{~h}$ without contact inhibition in regular growth medium [15]. Temperature-sensitive SV40 LTA-immortalized cell lines cultured at $33^{\circ} \mathrm{C}$ have been successfully expanded to 30 passages with a doubling time of about 3 days (varied between approximately 48 and $96 \mathrm{~h}$ ), with loss of proliferative capacity associated with senescence observed when cultured at $37^{\circ} \mathrm{C}$ [19]. The full repertoire of mitogens, cofactors and growth factor receptors required for endoneurial endothelial cell proliferation are currently unknown.

Culture on surfaces coated with type I rat tail collagen seems to be necessary for in vitro proliferation and the formation of confluent BNB monolayers. Several mitogens, including vascular endothelial growth factor (VEGF), are included in specialized media or growth supplements described to culture primary and immortalized HEndECs. PnMECs have been shown to also express VEGF, but not angiopoietin, basic fibroblast growth factor (bFGF) or transforming growth factor (TGF)- $\beta_{1}$ by Western blot [17]. Endogenous VEGF expression implies a possible autocrine effect on cellular proliferation. In the embryonic rodent brain, high levels of VEGF receptors, VEGFR1 and VEGFR2, have been described during angiogenesis, with low levels observed in the adult $\mathrm{BBB}$ en- dothelium [23]. VEGF is also widely known to modulate mammalian microvascular permeability, with the formation of adrenal cortex capillary endothelial fenestrations in vitro [24]. VEGF has also been implicated in altering TJ protein expression by PnMECs following exposure to advanced glycation end-products (mimicking diabetic conditions) in vitro [25]. The dose-dependent effects of VEGF and the expression profile of its signaling receptors by human BNB-forming endothelial cells in vitro under different experimental conditions require further investigation.

Glial cell-derived neurotrophic factor (GDNF) and nerve growth factor were not expressed by PnMECs in vitro by PCR or Western blot, while messenger RNA (mRNA) for brain-derived neurotrophic factor without protein expression by Western blot has been described [17]. Interestingly, these primary cells express the glycosylphosphatidylinositol-anchored membrane protein receptor for GDNF, GFRa1, suggesting responsiveness to exogenous GDNF $[18,26]$. In support of this, GDNF upregulated pHEndEC GFRa1 expression as a response to diffuse endothelial injury induced by serum withdrawal in vitro, suggesting a positive feedback loop [26].

\section{Adherens Junction and TJ Proteins}

Intercellular adherens junctions (AJs) and TJs, and their associated binding, signaling/regulatory proteins are essential characteristics of restrictive barrier-forming microvascular endothelium [27-30]. Primary and immortalized HEndECs have been shown to express mRNA transcripts or protein for claudin-1, claudin-2, the endothelial specific claudin-5, claudin-12 and claudin-19, as well as occludin, zona occludens (ZO)-1, ZO-2, junctional adhesion molecule-A (JAM-A), vascular endothelial (VE)-cadherin and $\beta$-catenin $[14,17-19,26]$ (table 1). However, mRNA or protein expression does not necessarily imply localization at sites of intercellular contacts required for AJ and TJ formation. Similarly, contamination of purified HEndEC cultures by myelinating Schwann cells (known to form autotypic TJs in noncompacted myelin components between adjacent membrane lamellae of the same Schwann cell in vivo and in situ) could confound these assays [31,32]. Immunocytochemistry of confluent cultures has demonstrated expression of AJ protein VE-cadherin, and $\mathrm{TJ}$ proteins claudin- 5 and occludin and $\mathrm{TJ}$-associated proteins ZO-1 and ZO-2 at sites of cell-to-cell contact [14, $19,26]$. Interestingly, pHEndECs demonstrated nuclear expression of claudin-1, with perinuclear claudin-2 and 
Table 1. HEndEC AJ and TJ protein expression

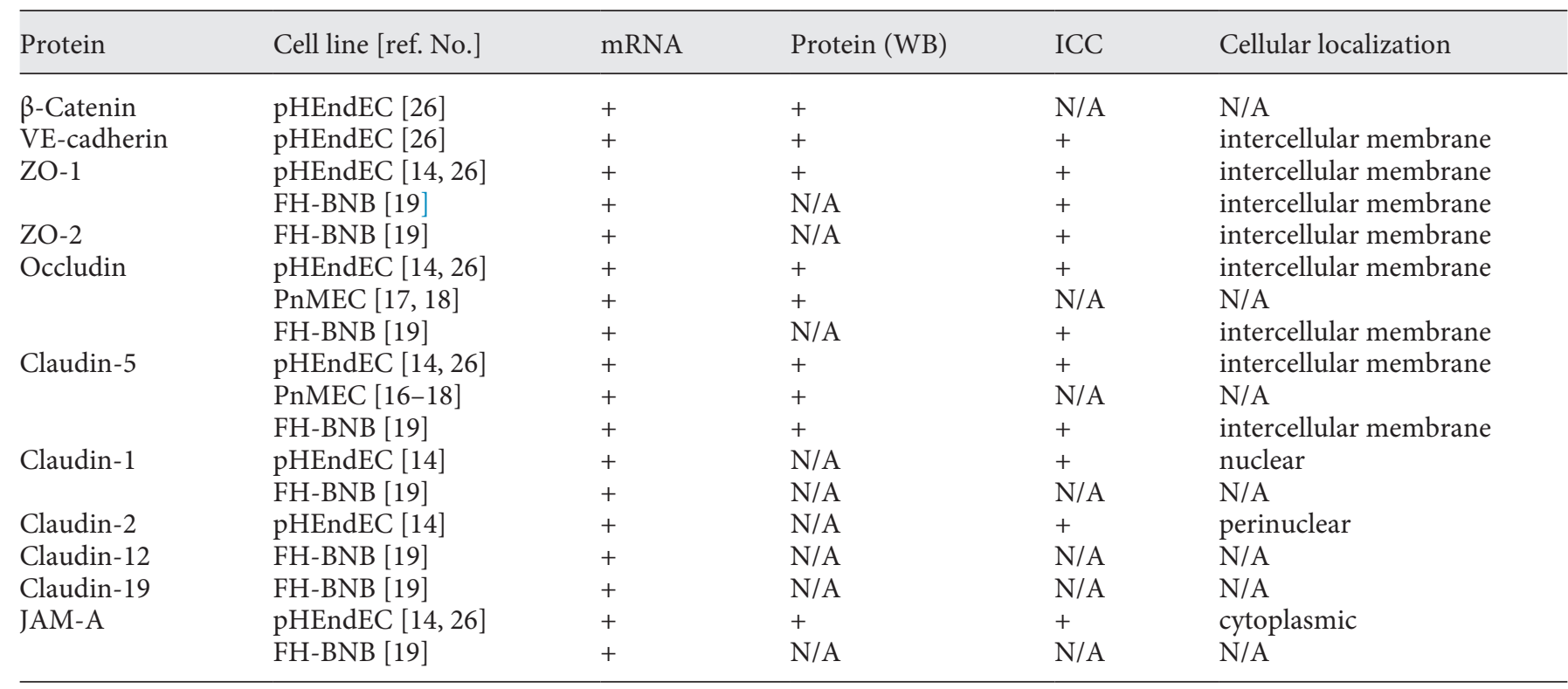

FH-BNB = Conditionally immortalized human PnMECs; WB = Western blot; ICC = immunocytochemistry; + = detected; N/A = not assessed.

diffuse cytoplasmic JAM-A expression in vitro [14], suggesting that these molecules may not actively participate in human BNB function under normal conditions.

Conditioned medium from immortalized human peripheral nerve pericyte lines, as well as bFGF, hydrocortisone and GDNF, has been reported to induce claudin-5 protein levels ( $~ 50 \%$ of untreated levels) within $24-48 \mathrm{~h}$ of plating primary or immortalized BNB-forming endothelial cells at high density without significant changes in occludin [16-18]. Thus, it has been postulated that claudin-5 expression at the BNB is primarily responsible for its TJ barrier characteristics. However, immunocytochemical evidence demonstrating increased claudin-5 expression at intercellular contacts is lacking in these reports. In a model of diffuse endothelial injury of confluent pHEndEC cultures, GDNF at low nanomolar concentrations that maximally restored barrier function failed to induce mRNA transcripts or protein expression for $\beta$-catenin, VE-cadherin, ZO- 1 or occludin relative to basal untreated conditions. There was a small increase in total claudin-5 protein ( $30 \%$ of basal levels), without significant differences in mRNA expression or claudin- 5 tyrosine phosphorylation [26].

Observational in situ immunohistological data from developing and adult human sciatic nerves demonstrated equivalent endoneurial microvessel claudin- 5 expression during neonatal development (when the BNB is immature and permissive based on rodent work) when compared to adult nerves $[7,8]$. Published in vitro immunocytochemistry data have shown that the GDNF-induced improvement in human BNB TJ barrier function following serum withdrawal was dependent on 'rearranged during transfection' (RET)-tyrosine kinase signaling pathways (RET is the receptor for members of the GDNF family of extracellular signaling molecules) associated with F-actin cytoskeletal filament relocation towards cytoplasmic membranes, resulting in more continuous intercellular AJs and TJs with fewer noncontinuous spaces between adjacent cells [26]. This is congruent with studies in rodent embryonic brains and neonatal rat sciatic nerves that also demonstrate that $\mathrm{TJ}$ barrier maturation is associated with cytoskeletal rearrangements and disappearance of clefts between endothelial cells $[8,28,33]$.

Work is needed to deduce the full repertoire of $\mathrm{AJ}$ and TJ proteins expressed at the human BNB, as well as the temporal relationship between protein expression and translocation to intercellular junctions with resultant restrictive barrier function. Differences in the repertoire and distribution of $\mathrm{AJ}$ and $\mathrm{TJ}$ proteins between human and mouse myelinating Schwann cells in adult peripheral nerves [32] further emphasize the need to perform expression profile studies using pHEndECs for in situ test- 


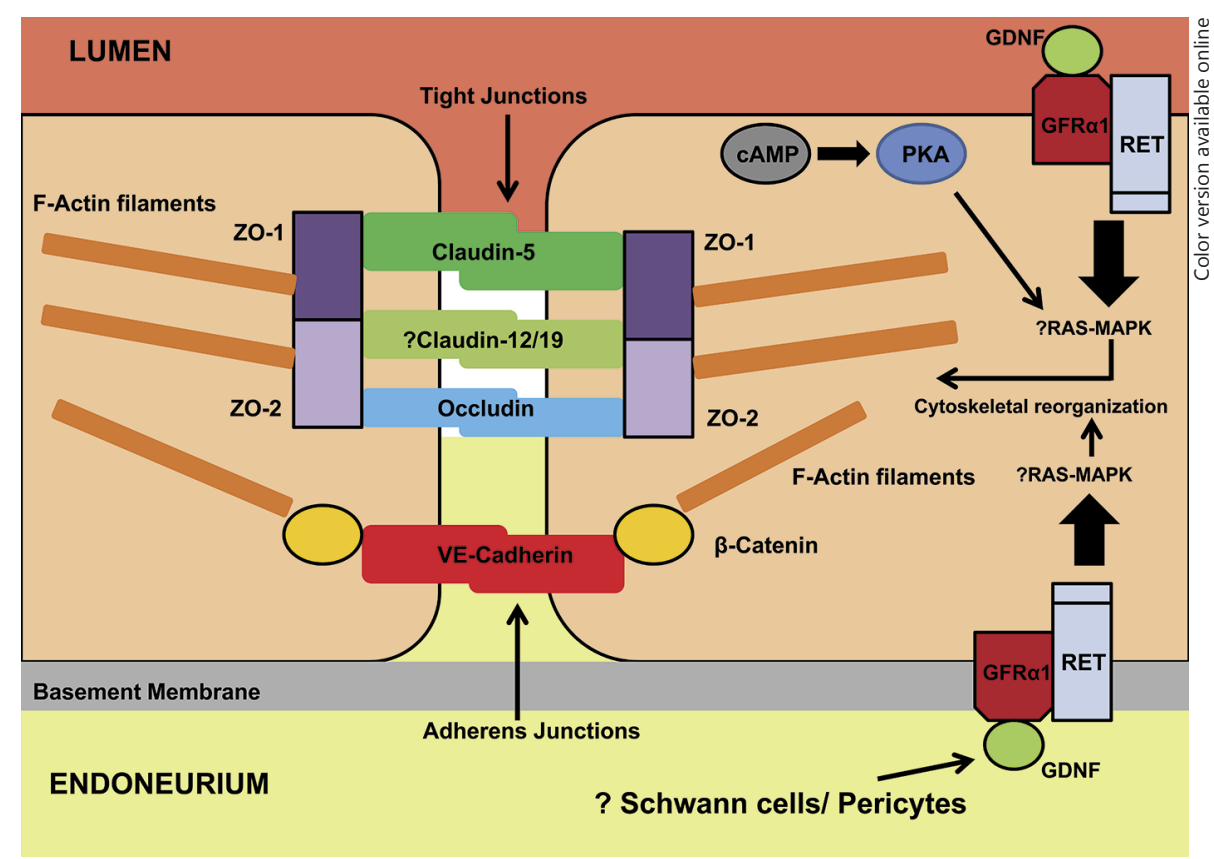

Fig. 2. Human BNB intercellular junctional complex. This figure illustrates the known $\mathrm{AJ}$ and $\mathrm{TJ}$ proteins expressed by the human BNB in vitro, and their accessory or regulatory proteins and their membrane localization guided by knowledge of other restrictive barrier-forming endothelial cells. There is immunocytochemistry evidence for ZO-1, ZO-2, claudin-5, occludin and VE-cadherin expression at intercellular contact sites, without direct evidence for claudin-12 and claudin-19. pHEndEC $\beta$-catenin expression has been demonstrated by PCR and Western blot. GFR $\alpha 1$, the receptor for GDNF, complexed with RET, is expressed by pHEndECs and mediates recovery of restrictive barrier characteristics at the human BNB in vitro following serum withdrawal, dependent on RET tyrosine kinase-mediated signaling. There is preliminary evidence that the Ras-MAPK signaling pathway acts downstream of RET, with the net effect being cytoskeletal reorganization of F-actin filaments, with relocation towards the cytoplasmic membrane and intercellular contact sites, providing the scaffold for more continuous $\mathrm{AJ}$ and TJ and fewer intercellular clefts. Cyclic adenosine monophosphate (cAMP), acting via protein kinase A (PKA) has been shown to play a minor role in this process, independent of GDNF, with a mild additive effect observed when multiple mitogens are administered to induce pHEndEC recovery from diffuse endothelial injury. Schwann cells and pericytes are potential cellular sources for GDNF in peripheral nerves. ing on human endoneurial microvessels in peripheral nerve biopsies. These studies could provide insights into normal human BNB development and restoration of barrier function following injury such as hypoxia, trauma or toxic insult. Figure 2 depicts the known and hypothesized $\mathrm{AJ}$ and $\mathrm{TJ}$ proteins, and growth factor receptors expressed at the human $\mathrm{BNB}$, and the proposed relationship between GDNF and actin cytoskeletal reorganization during recovery from diffuse endothelial injury.

\section{Transporters}

As a restrictive microvascular barrier necessary to maintain the internal homeostatic microenvironment in peripheral nerves, the human BNB is expected to possess specialized transporters on its luminal and abluminal surfaces to facilitate directional influx of solutes, nutrients and macromolecules and efflux of waste products of metabolism or xenobiotics. Current knowledge on BNB transporters has been guided by expectations based on other restrictive microvascular barriers, such as the BBB, and observations in the peripheral nerves of other species [34-47]. In vivo human data, in situ data from human peripheral nerve biopsies and data from noncultured human BNB-forming endothelial cells are generally lacking. Hypothesized BNB transporters based on in vitro data from cultured HEndECs can be classified as ionic, nutrient and xenobiotic transporters (table 2).

Alkaline phosphatase (AP) is an enzyme that can be considered a capillary endothelium ionic transporter, as it can transfer phosphate groups, as well as serve as a membrane pump or cell adhesion molecule (CAM), in addition to the hydrolysis of phosphate esters [48-51]. AP is specifically expressed on capillary endothelial cells in several tissues, and, in mammalian peripheral nerves, it has been 
Table 2. Human BNB transporter expression in vitro

\begin{tabular}{|c|c|c|c|c|}
\hline Protein & $\begin{array}{l}\text { Cell line } \\
\text { [ref. No.] }\end{array}$ & mRNA & $\begin{array}{l}\text { Protein } \\
\text { (WB/FACS) }\end{array}$ & ICC \\
\hline \multirow[t]{2}{*}{$\mathrm{AP}$} & pHEndEC [14] & + & + & + \\
\hline & THEndEC [15] & + & + & $\mathrm{N} / \mathrm{A}$ \\
\hline \multirow[t]{3}{*}{ GLUT-1 } & pHEndEC [14] & + & + & + \\
\hline & THEndEC [15] & + & N/A & $\mathrm{N} / \mathrm{A}$ \\
\hline & FH-BNB [19] & + & + & $\mathrm{N} / \mathrm{A}$ \\
\hline \multirow[t]{2}{*}{ MCT-1 } & pHEndEC [14] & + & $\mathrm{N} / \mathrm{A}$ & $\mathrm{N} / \mathrm{A}$ \\
\hline & THEndEC [15] & + & + & $\mathrm{N} / \mathrm{A}$ \\
\hline \multirow[t]{2}{*}{ CRT } & pHEndEC [14] & + & $\mathrm{N} / \mathrm{A}$ & $\mathrm{N} / \mathrm{A}$ \\
\hline & THEndEC [15] & + & + & $\mathrm{N} / \mathrm{A}$ \\
\hline \multirow[t]{2}{*}{ LAT-1 } & pHEndEC [14] & + & N/A & $\mathrm{N} / \mathrm{A}$ \\
\hline & THEndEC [15] & + & + & $\mathrm{N} / \mathrm{A}$ \\
\hline \multirow{2}{*}{$\begin{array}{l}\gamma \text {-Glutamyl } \\
\text { transpeptidase }\end{array}$} & pHEndEC [14] & + & + & + \\
\hline & THEndEC [15] & + & + & $\mathrm{N} / \mathrm{A}$ \\
\hline \multirow{3}{*}{$\begin{array}{l}\text { P-gp/ } \\
\text { MDR1a }\end{array}$} & pHEndEC [14] & + & + & + \\
\hline & THEndEC [15] & + & + & N/A \\
\hline & FH-BNB [19] & + & + & N/A \\
\hline MRP-1 & FH-BNB [19] & + & N/A & N/A \\
\hline OATP-C & THEndEC [15] & $\mathrm{N} / \mathrm{A}$ & + & $\mathrm{N} / \mathrm{A}$ \\
\hline OAT-3 & THEndEC [15] & $\mathrm{N} / \mathrm{A}$ & + & $\mathrm{N} / \mathrm{A}$ \\
\hline
\end{tabular}

pTHEndEC $=$ SV40 LTA immortalized HEndECs; FH-BNB = conditionally immortalized human PnMECs; $\mathrm{WB}=$ Western blot; FACS = fluorescent-activated cell sorting; ICC $=$ immunocytochemistry; + = detected; N/A = not assessed.

shown to discriminate between endoneurial and epineurial vessels [5]. AP expression has been demonstrated on primary and immortalized HEndECs in vitro. Loss of AP expression was observed with immortalized HEndECs at higher passages [14, 15]. It is hypothesized that other ionic transporters that may maintain ionic concentrations within the endoneurium are expressed at the BNB. The putative monovalent and divalent adenosine triphosphate (ATP)-dependent and independent transporters present on the BNB are currently unknown.

Nutrient transporters are presumed to facilitate the transport of glucose, amino acids and lipids from the blood circulation into the endoneurium. GLUT-1, the major glucose transporter in the body, is highly expressed by HEndECs, including serially passaged immortalized cells $[14,15]$. GLUT-1 has been described in situ on adult and developing sciatic nerve endoneurial capillaries by indirect immunofluorescence [52].This implies an im- portant role for facilitated transport of D-glucose into the endoneurium as a source of energy under normal conditions [35]. MCT-1, a major transporter for monocarboxylic acids such as L-lactate, is similarly expressed by primary and immortalized HEndECs [14, 15], implying a role as an influx transporter, bringing L-lactate from the bloodstream for energy utilization during periods of starvation or as an efflux transporter, removing lactate from the endoneurium as an aerobic metabolic by-product or following anaerobic metabolism following axonal or Schwann cell injury [53]. Creatine transporter (CRT) carries creatine (required for the temporary storage of highenergy phosphate groups) across vascular endothelium. Creatine provides a high-energy phosphate reservoir needed for ATP generation during periods of high metabolic activity [40]. CRT expression has been demonstrated on human primary and immortalized BNB-forming endothelial cells $[14,15]$, implying that creatine transport into the endoneurium may be necessary for normal peripheral nerve function.

LAT-1, the $\mathrm{Na}^{+}$-independent L-type amino acid transporter 1 which forms a heterodimer with $4 \mathrm{~F} 2$ cell surface antigen heavy chain, is known to preferentially transport neutral and aromatic amino acids, such as L-phenylalanine and L-tryptophan $[47,54]$. LAT- 1 is expressed by primary and immortalized HEndECs [14, 15], implying an important role as an influx transporter for this class of amino acids for energy utilization within peripheral nerves. $\gamma$-Glutamyl transpeptidase, a known transporter of amino acids across restrictive barrier-forming endothelium $[36,41,51,55]$ that also functions as an enzyme that catalyzes the transfer of the $\gamma$-glutamyl moiety of glutathione to an acceptor (amino acid, peptide or water), is expressed by these cells $[14,15]$, providing another means by which amino acids can be transported across the BNB. Its catalytic function could also provide a pathway for drug and xenobiotic detoxification in peripheral nerves.

Xenobiotic transporters demonstrated thus far to be expressed by primary or immortalized human endoneurial cells include members of the ABC (ATP-binding cassette) or multidrug resistance and organic anion transporter (OAT) families. ABC transporters include P-glycoprotein (P-gp; also known as MDRla or multidrug resistance gene 1a), a major efflux transporter for chemotherapeutic drugs such as vincristine, and multidrug resistance protein-1 (MRP1), an efflux transporter with significant substrate overlap with P-gp $[14,15,19]$. MRP1 may transport a broader range of xenobiotics used as antineoplastic or therapeutic agents including folate-based antimetabolites, anthracyclines, vinca alkaloids, anti-an- 
Fig. 3. Human BNB transporters. This figure depicts the known transporters and their putative cellular localization and actions at the BNB based on PCR, Western blot, flow cytometry and immunocytochemical studies performed with primary and immortalized HEndECs in vitro. The influx transporters are shown on the luminal side, while efflux transporters are shown on the abluminal side. It is hypothesized that MCT-1 may play a dual role as an influx and efflux transporter dependent on endoneurial energy requirements and the presence of toxic metabolites. AJs and TJs should prevent paracellular transport of small polar molecules from the bloodstream into the endoneurium. Weibel-Palade bodies (WPB), known to contain von Willebrand factor and P-selectin, are also shown. $\gamma$-GT $=\gamma$-Glutamyl transpeptidase.

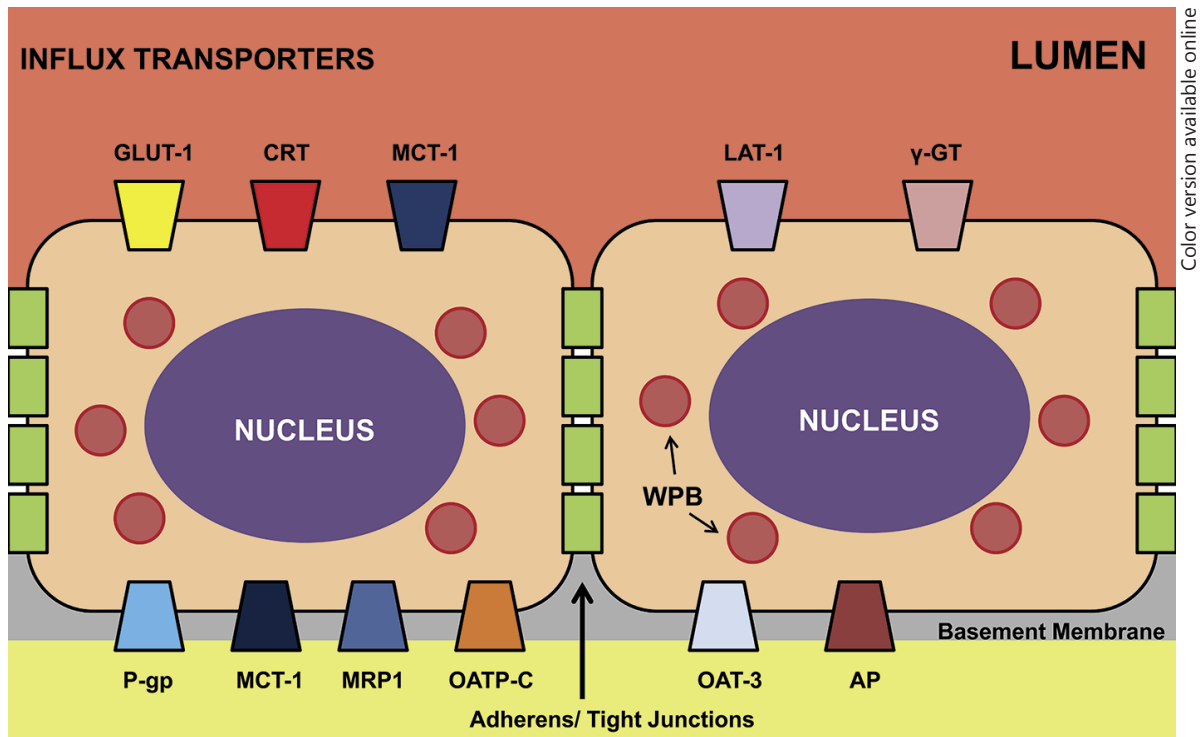

EFFLUX TRANSPORTERS
ENDONEURIUM drogens, and numerous glutathione (GSH) and glucuronide conjugates of these compounds as well as organic anions and heavy metals. MRP1 also transports diverse physiological substrates such as folates, GSH and GSH disulfide (GSSG), as well as sulfate, GSH and glucuronide conjugates of steroids, leukotrienes and prostaglandins $[47,56,57]$. The activities of P-gp and MRP1 may be important for the protection of peripheral nerves from toxic insult as well as in normal cellular processes such as export of endogenous metabolic intermediates [47, 56-58].

Immortalized HEndECs express the OATs OAT polypeptide-C (OATP-C) and OAT-3 at similar levels to immortalized brain microvascular endothelial cells that form the BBB [15]. OATP-C is a member of a family of solute carriers that function as $\mathrm{Na}^{+}$and ATP-independent transporters for amphipathic organic compounds such as steroids, thyroid hormones, anionic peptides, drugs (such as 3-hydroxy-3-methyl-glutarylcoenzyme A reductase inhibitors) and xenobiotics $[47,59,60]$. OAT-3 is involved in the transport and excretion of drugs such as benzyl penicillin, methotrexate, ciprofloxacin, indomethacin and cimetidine, and toxic organic ions. OAT-3 also functions as an organic anion exchanger, coupling the uptake of one organic anion molecule with the efflux of one endogenous dicarboxylic acid molecule [47, 61, 62]. It is speculated that these OATs, which serve as efflux transporters, may protect axons and Schwann cells within the endoneurium from the toxic effects of these organic molecules and compounds.
Further work is needed to determine the full repertoire of transporters expressed at the human BNB. Studies may be focused on elucidating their cellular membrane localization (luminal or abluminal, or both) and influx and efflux kinetic characteristics for a variety of substrates and decipher what adaptations may occur to maintain normal substrate transport. This information should result in detailed comprehension of the metabolic requirements of peripheral nerves in health, during starvation and at times of stress, as well as provide insights into targeted drug delivery into peripheral nerves and the prevention of drug-induced toxicities. Figure 3 illustrates the currently known transporters expressed at the human $\mathrm{BNB}$ in vitro and their hypothesized cellular localization.

\section{CAMs and Chemokines}

Hematogenous leukocyte trafficking across microvascular endothelium is an evolutionally conserved characteristic required for normal tissue immunosurveillance, as well as response to injury, inflammation or infection, proving an essential link between the innate and adaptive immune responses. Aberrant leukocyte trafficking has been described as a pathological hallmark of autoimmune neuropathies. Leukocyte trafficking is a coordinated, sequential process that involves the interaction of selectins and their carbohydrate counterligands with properties similar to C-type lectins (e.g. sialyl Lewis $\mathrm{x}$ ), chemokines 
and other chemoattractant molecules and their receptors, integrins interacting with specific CAMs and matrix metalloproteinases that facilitate extravasation across endothelial basement membranes [63-66].

pHEndECs express E- and P-selectin at early passages $(<8)$ in vitro $[14,67]$, as well as CD34, a transmembrane sialomucin glycoprotein that is expressed on vascular endothelial cells, particularly capillaries, and is known to mediate L-selectin-dependent $\mathrm{T}$-cell homing into high endothelial venules in lymph nodes $[14,68$, 69]. These cells also express intercellular adhesion molecule-1 (ICAM-1: interacts with $\alpha_{L} \beta_{2}$ and $\alpha_{M} \beta_{2}$ integrins), JAM-A (interacts with $\alpha_{\mathrm{L}} \beta_{2}$, and implicated in leukocyte adhesion and migration in some models of inflammation) [70], vascular CAM-1 (VCAM-1) and the alternatively spliced fibronectin variant called fibronectin connecting segment-1 (FN CS-1), which contains the conserved leucine-aspartic acid-valine peptide sequence required for integrin binding $[14,67]$. The latter two CAMs interact with $\alpha_{4} \beta_{1}$ integrin. Platelet endothelial CAM (PECAM-1), also known as CD31, a major component of endothelial cell intercellular junctions that may participate in angiogenesis, integrin activation and leukocyte migration [70, 71], has been demonstrated on immortalized PnMECs [19].

Following physiological proinflammatory cytokine treatment of confluent cultures for up to $48 \mathrm{~h}$ in vitro, there was a time-dependent increase in E-selectin, P-selectin, ICAM-1, VCAM-1 and FN-CS1 without change in JAM-A expression, reaching maximum levels by $24 \mathrm{~h}$ [67]. These data imply a role for these adhesion molecules in the recruitment of hematogenous leukocytes under normal and inflammatory conditions. In support of this, $\alpha_{M} \beta_{2}$ integrin-ICAM-1 interactions have been shown to mediate the adhesion and transmigration of pathogenic mononuclear leukocytes derived from patients with Guillain-Barré syndrome at the human BNB in vitro using a flow-dependent model that mimics capillary hemodynamics [67].

Chemokines or chemotactic cytokines are small 8- to $14-\mathrm{kDa}$ molecules that attract leukocytes across concentration and haptotactic gradients in vitro and in vivo, signaling via G-protein-coupled receptors. Chemokines are classified into four subfamilies based on the organization of two positionally conserved cysteine residues near the N-terminus: the CXC $(\alpha)$, CC $(\beta), \operatorname{CX3C}(\delta)$ and C $(\gamma)$ subfamilies. Chemokines are also involved in embryogenesis, normal neuronal-glial interactions, neuronal protection from toxins and synaptic transmission, reflecting their importance in the development and homeo- stasis in addition to inflammation [72-74]. Using an in vitro chemokine antibody array, confluent pHEndECs were shown to constitutively express CXCL1-CXCL3, CXCL5, CXCL7, CXCL8, CXCL10, CCL4, CCL5, CCL22, CCL23, CCL24 and CCL26, suggesting homeostatic roles for these chemokines (e.g. immune surveillance) at the human BNB [67].

Physiological doses of proinflammatory cytokines induced de novo cytoplasmic expression of CCL2, CCL20, CCL27, CXCL9 and CXCL11 at the BNB in vitro, as well as a 5.8-fold increase in CXCL2-CXCL3, 4.4-fold increase in CXCL8 and 2.5-fold increase in CXCL10 expression. Less than 2-fold increases in CCL4, CCL5, CCL23, CXCL5 and CXCL7 were also observed. CCL26 was reduced to 0.9-times its basal levels, without significant change in CCL22 and CCL24 expression. These observations suggest potential activation of the innate (i.e. neutrophil-dependent: CXCL2-CXCL3, CXCL8 interacting with chemokine receptors CXCR1 and CXCR2; monocyte-dependent: CCL2 interacting with CCR2) and adaptive (i.e. T-cell-dependent: CXCL9, CXCL10 and CXCL11 interacting with CXCR3 on CD4+ T-helper 1 cells, CCL20 interacting with CCR6 on CD4+ T-helper17 cells and CCL27 interacting with CCR10 on activated T cells) immune signaling pathways at the human BNB at the early stages of inflammation [67].

Further work is needed to decipher which chemokines are most relevant for specific leukocyte subpopulation recruitment into the peripheral nerve endoneurium across the $\mathrm{BNB}$ during immunosurveillance and in inflammatory states. It is currently unknown which chemokine receptors are expressed by endoneurial endothelial cells, as this may shed further light on directional angiogenesis during peripheral nerve development and recovery from injury. Figure 4 demonstrates the currently known array of CAMs expressed by the human BNB and the effect of physiological proinflammatory cytokine exposure in vitro.

\section{Biophysical Characterization of the in vitro Human BNB}

Based on mammalian in vivo studies, the BNB is second only to the $\mathrm{BBB}$ in terms of restrictive endothelial barrier properties in the body [1, 6, 42, 75-78]. Electrondense intercellular contacts, consistent with TJs, have been demonstrated between HEndECs in situ and in vitro $[3,4,14]$. Primary and immortalized HEndECs have been cultured to confluence in Transwell systems or specialized tissue culture plates to ascertain their biophysical 


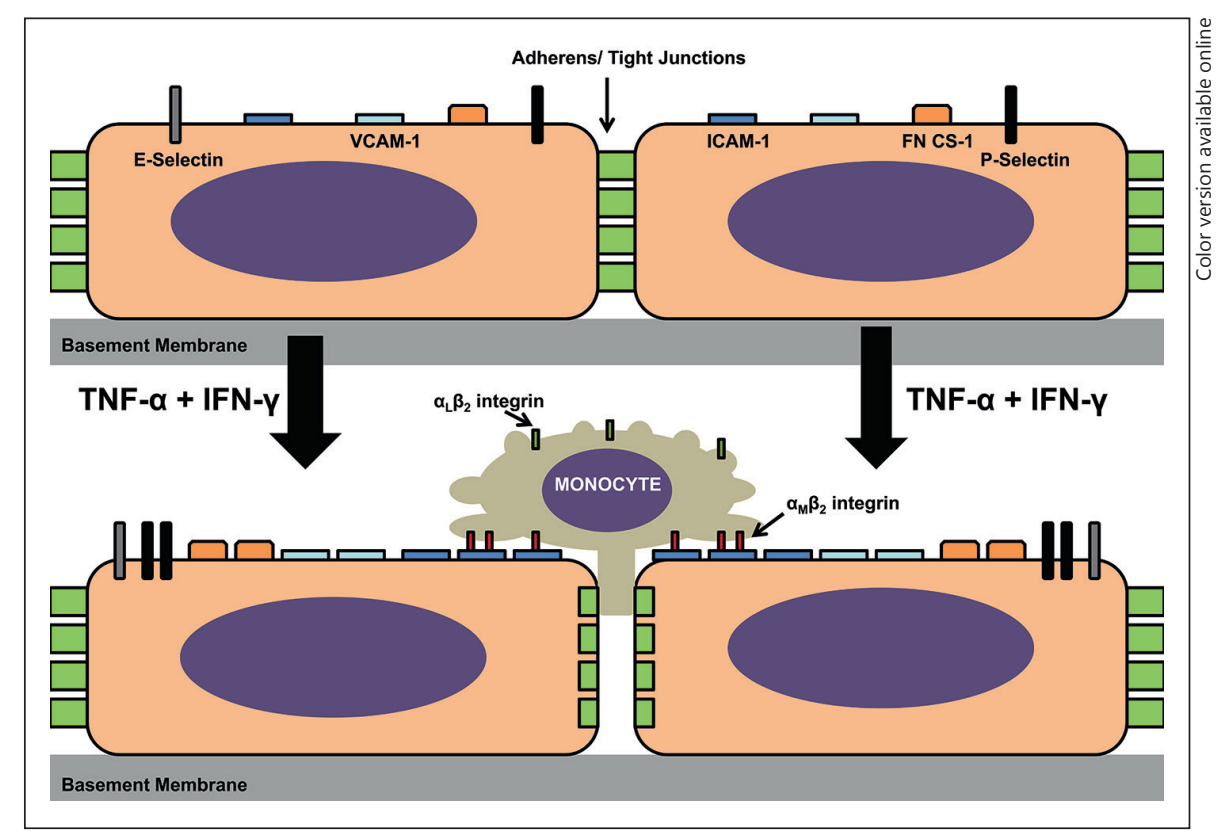

Fig. 4. HEndEC adhesion molecules and effect of proinflammatory cytokines. The constitutive expression of CAMs by the human $\mathrm{BNB}$ in vitro is depicted in the upper image, with a time-dependent increase in cytoplasmic protein expression observed following exogenous treatment of confluent cultures with $10 \mathrm{U} / \mathrm{ml} \mathrm{TNF-} \alpha$ and $20 \mathrm{U} / \mathrm{ml}$ interferon (IFN)- $\gamma$ over $48 \mathrm{~h}$. CD31 and CD34 expression has been described, but the effect of cytokine treatment on their expression has not been evaluated. Cytoplasmic JAM-A expression by pHEndECs has been reported in vitro, but its expression was not regulated by proinflammatory cytokine treatment (not shown). Using a flow-dependent in vitro BNB-leukocyte trafficking model, ICAM-1 significantly contributed to pathogenic peripheral blood mononuclear cell adhesion and transmigration, de-

properties as TJ-forming barriers in vitro. Endothelial biophysical properties may be divided into transendothelial electrical resistance (TEER), solute permeability and hydraulic conductivity.

\section{Transendothelial Electrical Resistance}

The human BNB TEER in vivo is currently unknown, but estimated to be similar to the BBB. Using Transwell systems, published mean in vitro TEER values vary between $~ 20-35$ [16-19] and $~ 110-180 \Omega \mathrm{cm}^{2}[14,15,26$, 67] depending on the experimental conditions, and whether primary or immortalized endothelial cells were studied. Using continuous electrical cell impedance sensing, TEER values $>250 \Omega$ have been observed [unpubl. observations]. Several factors have been shown to influ- pendent on interactions with $\alpha_{M} \beta_{2}$ integrin, rather than its more ubiquitously expressed counterligand, $\alpha_{\mathrm{L}} \beta_{2}$ integrin. Video microscopy shows that these mononuclear cells firmly arrest and congregate at contact sites between confluent endothelial cells, with a subset of leukocytes slowly migrating across the BNB via the paracellular route without significant retraction of neighboring endothelial cells from each other during the course of a 30-min assay with estimated in vivo capillary flow rates based on red blood cell velocities (refer to published supplementary data for reference [61] for videos). Further studies are needed to determine whether transcellular trafficking occurs at the human BNB in vitro and in vivo, as observed in other microvascular transmigration model systems. ence human BNB TEER in vitro, including seeding density at the time of initial plating, constitution of the extracellular matrix used to culture endothelial cells, coculture with astrocyte and immortalized human brain and peripheral nerve pericyte-conditioned media and several mitogens including GDNF, bFGF, TGF- $\beta_{1}$ and hydrocortisone (in a concentration-dependent manner), cyclic adenosine monophosphate and time after initial plating [14$19,26]$. Based on observations with pHEndECs, TEER may peak and plateau 5-12 days after initial plating [14, $15,26]$. The significant discrepancy between published in vitro human BNB TEER values may reflect differences in initial seeding density and the time when TEER was measured after initial plating on Transwell systems $\left(>3 \times 10^{6}\right.$ cells $/ \mathrm{cm}^{2}$ and 1-2 days associated with lower TEER values [16-19], compared to 250,000 cells $/ \mathrm{cm}^{2}$ and 5-12 days with higher TEER values $[14,15,26])$, as shown in table 3 . 
Table 3. Biophysical properties of the human in vitro BNB

\begin{tabular}{|c|c|c|c|c|}
\hline $\begin{array}{l}\text { BNB endothelial } \\
\text { cell line [ref. No.] }\end{array}$ & Culture conditions & $\begin{array}{l}\text { Assay time } \\
\text { days }\end{array}$ & $\begin{array}{l}\text { TEER } \\
\Omega \mathrm{cm}^{2}\end{array}$ & Solute permeability (tracer/value) \\
\hline $\begin{array}{l}\text { pHEndEC } \\
{[14,26,67]}\end{array}$ & $\begin{array}{l}250,000 \text { cells } / \mathrm{cm}^{2}, \text { rat tail collagen- } \\
\text { coated Transwell inserts, } 3-\mu \mathrm{m} \text { pore size }\end{array}$ & $\begin{array}{c}5-7 \\
10-12\end{array}$ & $\begin{array}{l}\sim 110-130^{\mathrm{a}} \\
\sim 140-160\end{array}$ & $\begin{array}{l}70 \text { kDa dextran-FITC (<5\% input @ } 15 \mathrm{~min}) \\
70 \mathrm{kDa} \text { dextran-FITC }(0.7 \% \text { input @ } 15 \mathrm{~min})\end{array}$ \\
\hline $\begin{array}{l}\text { THEndEC } \\
{[15]}\end{array}$ & $\begin{array}{l}250,000 \text { cells } / \mathrm{cm}^{2} \text {, glutaraldehyde- } \\
\text { cross-linked rat tail collagen-coated } \\
\text { Transwell inserts, } 3-\mu \mathrm{m} \text { pore size }\end{array}$ & 7 & $\sim 180$ & $\begin{array}{l}\text { sodium-FITC (4.84\% input @ } 15 \mathrm{~min}) \\
70 \mathrm{kDa} \text { dextran-FITC (0.39\% input @ } 15 \mathrm{~min})\end{array}$ \\
\hline $\begin{array}{l}\text { PnMEC } \\
{[17,18]}\end{array}$ & $\begin{array}{l}3,000,000 \text { cells } / \mathrm{cm}^{2} \text {, rat tail collagen- } \\
\text { coated Transwell inserts, } 0.4-\mu \mathrm{m} \text { pore size }\end{array}$ & 2 & $\sim 20-35^{\mathrm{b}}$ & [carboxyl $\left.{ }^{-14} \mathrm{C}\right]$ inulin $(10-15 \mu \mathrm{l} @ 20 \mathrm{~min})$ \\
\hline $\begin{array}{l}\text { DH-BNB/ } \\
\text { FH-BNB [16] }\end{array}$ & $\begin{array}{l}3,000,000 \text { cells } / \mathrm{cm}^{2} \text {, rat tail collagen- } \\
\text { coated Transwell inserts, } 0.4-\mu \mathrm{m} \text { pore size }\end{array}$ & $1-2$ & $\sim 20-30^{c}$ & N/A \\
\hline $\begin{array}{l}\text { DH-BNB/ } \\
\text { FH-BNB [19] }\end{array}$ & $\begin{array}{l}30,000 \text { cells } / \mathrm{cm}^{2} \text {, rat tail collagen- } \\
\text { coated Transwell inserts, } 0.4-\mu \mathrm{m} \text { pore size }\end{array}$ & $1-2$ & $\sim 30-40$ & $\begin{array}{l}\text { sodium-FITC }\left(0.60 \times 10^{-3} \mathrm{~cm} / \mathrm{min} \text { over } 1 \mathrm{~h}\right) \\
4 \mathrm{kDa} \text { dextran-FITC }\left(0.34 \times 10^{-3} \mathrm{~cm} / \mathrm{min}\right. \\
\text { over } 1 \mathrm{~h})\end{array}$ \\
\hline
\end{tabular}

Assay time = Assay time after plating; THEndEC = SV40 LTA immortalized HEndECs; DH-BNB/FH-BNB = conditionally immortalized human PnMECs; N/A = not assessed.

${ }^{a}$ Enhanced by GDNF > TGF- $\beta_{1}>$ bFGF $>$ hydrocortisone > cAMP/protein kinase A following diffuse endothelial injury (not affected by physiological doses of TNF- $\alpha$ and IFN- $\gamma$ ).

${ }^{b}$ Enhanced by coculture with astrocyte, immortalized brain and peripheral nerve pericyte-conditioned media and GDNF.

${ }^{\mathrm{c}}$ Enhanced by hydrocortisone.

The human BNB is unlike the BBB which has a glia limitans surrounding its microvascular endothelial cells. The glia limitans is formed by astrocyte and microglial foot processes that further contribute to barrier function $[27,28,36,79,80]$. Due to ultrastructural changes in intercellular junctions observed in peripheral nerve microvessels once they cross the inner perineurial layer into the endoneurium [3], it is hypothesized that cellular or molecular components restricted to the endoneurium are important for maintaining the specialized BNB characteristics. It is unknown whether peripheral nerve pericytes, which share a common basement membrane with endoneurial endothelial cells, directly contribute to barrier function in vivo or secrete mitogens as described by immortalized cells in vitro $[17,18]$.

Following diffuse endothelial injury mediated by serum withdrawal in vitro, GDNF potently induced human BNB TEER recovery within $48 \mathrm{~h}$ at low nanomolar concentrations (0.03 nM), dependent on RET-tyrosine kinase signaling pathways, independent of maximal concentrations of other mitogens (TGF- $\beta_{1}$, bFGF and hydrocortisone) that were capable of restoring TEER, albeit less efficiently and at higher molar concentrations within the nanomolar range (suggesting redundancy that may be essential for normal biologic function in vivo) [26]. Schwann cells are glial cells present in the peripheral nervous system [81] that are restricted to the endoneurium and are known to secrete GDNF in vitro [82]. Increased Schwann cell GDNF expression has also been described following rat sciatic nerve injury and human nerve root avulsion in vivo $[83,84]$. The potential role of Schwann cells in BNB development during embryogenesis and postnatal maturation, maintenance of $\mathrm{BNB}$ function and $\mathrm{BNB}$ recovery following injury has yet to be elucidated.

Increased leukocyte trafficking has been described in inflamed nerves, implying compromise or 'breakdown' of the BNB. Claudin-5 downregulation and altered ZO-1 localization has been described in endoneurial microvessels from peripheral nerves obtained from patients with chronic inflammatory neuropathies [85]. Thus, it is feasible that reduced TEER as a consequence of BNB compromise may occur. However, physiological proinflammatory cytokine treatment of confluent pHEndEC cultures grown on Transwell inserts for $24 \mathrm{~h}$ did not reduce TEER compared to untreated cultures [67], supporting the hypothesis that leukocyte trafficking at the BNB is an active rather than passive process, as hypothesized by the multistep paradigm. Based on initial in vitro flowdependent studies, leukocyte trafficking at the human 
BNB predominantly occurs via the paracellular route [67], suggesting that real-time alterations in TEER occur during inflammation. The effect of shear forces and the dynamic changes that may occur during leukocyte extravasation and their effects on BNB TEER are yet to be established.

\section{Solute Permeability}

Studies evaluating the permeability of the human BNB to some solutes and macromolecules (as a measure of barrier function) have been performed in vitro $[14,15,17]$. The permeability for any given solute or macromolecule across a restrictive microvascular barrier will depend on its size, polarity, lipophilicity and ability to undergo facilitated receptor-mediated transcytosis [30,47]. It can be hypothesized that smaller, nonpolar, highly lipophilic molecules with specific influx transporters may demonstrate the highest permeability across the BNB. Permeability coefficients (PCs) are commonly used to quantify solute permeability in vitro [30]. PC is dependent on the ratio of the transported solute concentration to its input concentration, the volume of the receiving well that collects the solute following transport, the endothelial surface area through which the solute undergoes transport and the assay time [86].

Mean PC values for the in vitro human BNB under resting conditions reported or calculated for sodium fluorescein (molecular weight $376 \mathrm{Da}$ ), radioactive inulin (molecular weight $\sim 4.5 \mathrm{kDa}$ ) and high-molecular-weight fluoresceinated dextran (molecular weight $70 \mathrm{kDa}$ ) are $\sim 20 \times 10^{-3}, \sim 10 \times 10^{-3}$ and $\sim 1.6-2.8 \times 10^{-3} \mathrm{~cm} / \mathrm{min}$, respectively $[14,15,17]$, demonstrating an inverse relationship between molecular weight and PC that is reportedly more pronounced at lower molecular weights [30]. A recent study using temperature-sensitive SV40 LTA-immortalized PnMECs surprisingly demonstrated a mean lower PC for low-molecular-weight fluorescently labeled dextran (molecular weight $4 \mathrm{kDa}: 0.34 \times 10^{-3} \mathrm{~cm} / \mathrm{min}$ ) than sodium fluorescein $\left(0.60 \times 10^{-3} \mathrm{~cm} / \mathrm{min}\right)$ [19]. Technical differences in endothelial cell plating and assay times, model Transwell systems, solute input concentrations and sampling of transported solute at predefined time points may account for these differences (table 3 ).

It is unknown how these $\mathrm{PC}$ values compare to the human BNB in vivo. Converting the mean PC of high-molecular-weight fluoresceinated dextran to a PC-surface area product would yield a value approximately 3-6-fold higher than the measured PC-surface area product for transferrin (molecular weight $80 \mathrm{kDa}$ ) in rat sciatic nerves [42]. The effects of capillary shear forces and the extracellular matrix, as well as Schwann cells, perineurial cells or pericytes (or combinations thereof) in enhancing BNB function in vivo are currently unknown, although it is hypothesized that shear forces could enhance TEER and reduce permeability to multiple solutes in vitro, as observed with a flow-dependent in vitro BBB model [80, 87].

Kinetic studies of solute, drug and macromolecular permeability using human in vitro BNB models should provide some insights into the regulation of the internal microenvironment of peripheral nerves and adaptations during stress or injury. Knowledge on how these substances are restricted from, permeate into or retained within the endoneurium following interactions with the BNB could enhance therapeutic strategies for peripheral neuropathies and neuropathic pain, or prevent toxic neuropathies, e.g. secondary to chemotherapeutic drugs such as vincristine or organic molecules such as alcohol and toluene.

\section{Hydraulic Conductivity}

Hydraulic conductivity (or transendothelial volume flow) can be described as a measure of the permissivity of water transport across a vascular barrier [30,88]. The specialized microenvironment of peripheral nerves is maintained by regulated blood-nerve fluid exchange directly across the endoneurial vascular endothelium and, in some instances, indirectly across the multilayered perineurium and turnover of endoneurial fluid by proximodistal convective fluid flow [2]. This fluid exchange is vital for the maintenance of endoneurial physiological parameters including blood flow, oxygen tension, $\mathrm{pH}$, oncotic pressure, hydrostatic pressure and ion concentrations [2]. Endoneurial edema is a well-known consequence of peripheral nerve injury and inflammation in vivo, implying dysfunction of, or limitations in, the adaptive capacity of the BNB to increased endoneurial fluid production in these disorders. There is currently no information on the hydraulic conductivity of the human BNB in vitro. Evaluating the determinants and mechanisms by which endoneurial endothelial cells transport water should provide further insights relevant to understanding fluid homeostasis within peripheral nerves and adaptations that may occur in peripheral nerve disease, particularly inflammatory neuropathies. 


\section{Conclusions}

This review summarizes current knowledge on the human BNB, driven predominantly by in vitro observations of primary and immortalized endoneurial endothelial cells. The relative dearth in healthy human peripheral nerve specimens and difficulties in performing functional, mechanism-driven assays to evaluate BNB function in healthy individuals could limit the confirmation of these initial observations with the BNB in situ and in vivo. Nonetheless, these cell lines provide an avenue to increase our understanding of the molecular and biophysical characteristics of the human BNB, elucidate the determinants and signaling pathways relevant to BNB formation, maturation and adaptation under normal physiological and pathophysiological states and initiate the process of enhancing or restricting drug delivery into peripheral nerves. Scientific in- vestigation of these human cell lines should foster the growth of this nascent and exciting field of microvascular biology.

\section{Acknowledgments}

Special thanks go to past and current members of the Neuromuscular Immunopathology Research Laboratory and collaborators who have assisted with the isolation, characterization and propagation of pHEndECs and immortalized HEndECs, and the development of the Transwell and flow-dependent human in vitro BNB model systems.

Research in the Neuromuscular Immunopathology Research Laboratory is currently supported by National Institutes of Health grants R21 NS073702 (2011-2013), R21 NS078226 (2012-2014), R01 NS075212 (2012-2017) and a subaward P30 AI27767 (20122014) to E.E.U. The content is solely the responsibility of the author and does not necessarily represent the official views of the National Institutes of Health.

\section{References}

1 Olsson Y: Microenvironment of the peripheral nervous system under normal and pathological conditions. Crit Rev Neurobiol 1990;5: 265-311.

2 Mizisin AP, Weerasuriya A: Homeostatic regulation of the endoneurial microenvironment during development, aging and in response to trauma, disease and toxic insult. Acta Neuropathol 2011;121:291-312.

- 3 Reina M, López A, Villanueva M, de Andrés J, León G: Morphology of peripheral nerves, their sheaths, and their vascularization (in Spanish). Rev Esp Anestesiol Reanim 2000; 47:464-475.

4 Reina M, López A, Villanueva M, De Andrés J, Machés F: The blood-nerve barrier in peripheral nerves (in Spanish). Rev Esp Anestesiol Reanim 2003;50:80-86.

5 Bell M, Weddell A: A descriptive study of the blood vessels of the sciatic nerve in the rat, man and other mammals. Brain 1984;107: 871-898.

6 Malmgren L, Olsson Y: Differences between the peripheral and the central nervous system in permeability to sodium fluorescein. J Comp Neurol 1980;191:103-107.

-7 Pummi K, Heape A, Grénman R, Peltonen J, Peltonen S: Tight junction proteins ZO-1, occludin, and claudins in developing and adult human perineurium. J Histochem Cytochem 2004;52:1037-1046.

8 Smith C, Atchabahian A, Mackinnon S, Hunter D: Development of the blood-nerve barrier in neonatal rats. Microsurgery 2001; 21:290-297.

-9 Hirakawa H, Okajima S, Nagaoka T, Takamatsu T, Oyamada M: Loss and recovery of the blood-nerve barrier in the rat sciatic nerve after crush injury are associated with expression of intercellular junctional proteins. Exp Cell Res 2003;284:196-210.

10 Bush MS, Reid AR, Allt G: Blood-nerve barrier: ultrastructural and endothelial surface charge alterations following nerve crush. Neuropathol Appl Neurobiol 1993;19:31-40.

11 Aird W: Phenotypic heterogeneity of the endothelium: I. Structure, function, and mechanisms. Circ Res 2007;100:158-173.

12 Aird W: Phenotypic heterogeneity of the endothelium: II. Representative vascular beds. Circ Res 2007;100:174-190.

13 Yano K, Gale D, Massberg S, Cheruvu P, Monahan-Earley R, Morgan E, Haig D, von Andrian U, Dvorak A, Aird W: Phenotypic heterogeneity is an evolutionarily conserved feature of the endothelium. Blood 2007;109: 613-615.

14 Yosef N, Xia R, Ubogu E: Development and characterization of a novel human in vitro blood-nerve barrier model using primary endoneurial endothelial cells. J Neuropathol Exp Neurol 2010;69:82-97.

15 Yosef N, Ubogu EE: An immortalized human blood-nerve barrier endothelial cell line for in vitro permeability studies. Cell Mol Neurobiol 2013;33:175-186.

16 Kashiwamura Y, Sano Y, Abe M, Shimizu F, Haruki H, Maeda T, Kawai M, Kanda T: Hydrocortisone enhances the function of the blood-nerve barrier through the up-regulation of claudin-5. Neurochem Res 2011;36: 849-855.

17 Shimizu F, Sano Y, Abe MA, Maeda T, Ohtsuki S, Terasaki T, Kanda T: Peripheral nerve pericytes modify the blood-nerve barrier function and tight junctional molecules through the secretion of various soluble factors. J Cell Physiol 2011;226:255-266.

18 Shimizu F, Sano Y, Saito K, Abe MA, Maeda T, Haruki H, Kanda T: Pericyte-derived glial cell line-derived neurotrophic factor increase the expression of claudin- 5 in the blood-brain barrier and the blood-nerve barrier. Neurochem Res 2012;37:401-409.

19 Abe M, Sano Y, Maeda T, Shimizu F, Kashiwamura Y, Haruki H, Saito K, Tasaki A, Kawai M, Terasaki T, Kanda T: Establishment and characterization of human peripheral nerve microvascular endothelial cell lines: a new in vitro blood-nerve barrier (BNB) model. Cell Struct Funct 2012;37:89-100.

20 Holthöfer H, Virtanen I, Kariniemi A, Hormia M, Linder E, Miettinen A: Ulex europaeus I lectin as a marker for vascular endothelium in human tissues. Lab Invest 1982;47:60-66.

21 Rondaij M, Bierings R, Kragt A, van Mourik J, Voorberg J: Dynamics and plasticity of Weibel-Palade bodies in endothelial cells. Arterioscler Thromb Vasc Biol 2006;26:10021007.

22 Takahashi K, Sawasaki Y, Hata J, Mukai K, Goto T: Spontaneous transformation and immortalization of human endothelial cells. In Vitro Cell Dev Biol 1990;26:265-274.

23 Risau W, Esser S, Engelhardt B: Differentiation of blood-brain barrier endothelial cells. Pathol Biol (Paris) 1998;46:171-175.

- 24 Esser S, Wolburg K, Wolburg H, Breier G, Kurzchalia T, Risau W: Vascular endothelial growth factor induces endothelial fenestrations in vitro. J Cell Biol 1998;140:947-959.
Human Blood-Nerve Barrier

Characterization
J Vasc Res 2013;50:289-303 DOI: $10.1159 / 000353293$ 
25 Shimizu F, Sano Y, Haruki H, Kanda T: Advanced glycation end-products induce basement membrane hypertrophy in endoneurial microvessels and disrupt the blood-nerve barrier by stimulating the release of TGF-beta and vascular endothelial growth factor (VEGF) by pericytes. Diabetologia 2011;54: 1517-1526.

-26 Yosef N, Ubogu EE: GDNF restores human blood-nerve barrier function via RET tyrosine kinase-mediated cytoskeletal reorganization. Microvasc Res 2012;83:298-310.

-27 Abbott N, Patabendige A, Dolman D, Yusof S, Begley D: Structure and function of the blood-brain barrier. Neurobiol Dis 2010;37: 13-25.

28 Wolburg H, Lippoldt A: Tight junctions of the blood-brain barrier: development, composition and regulation. Vascul Pharmacol 2002; 38:323-337.

29 Matter K, Aijaz S, Tsapara A, Balda MS: Mammalian tight junctions in the regulation of epithelial differentiation and proliferation. Curr Opin Cell Biol 2005; 17:453-458.

-30 Mehta D, Malik AB: Signaling mechanisms regulating endothelial permeability. Physiol Rev 2006;86:279-367.

-31 Miyamoto T, Morita K, Takemoto D, Takeuchi K, Kitano Y, Miyakawa T, Nakayama K, Okamura Y, Sasaki H, Miyachi Y, Furuse M, Tsukita S: Tight junctions in Schwann cells of peripheral myelinated axons: a lesson from claudin-19-deficient mice. J Cell Biol 2005; 169:527-538.

-32 Alanne MH, Pummi K, Heape AM, Grenman R, Peltonen J, Peltonen S: Tight junction proteins in human Schwann cell autotypic junctions. J Histochem Cytochem 2009;57:523529.

-33 Schulze C, Firth JA: Interendothelial junctions during blood-brain barrier development in the rat: morphological changes at the level of individual tight junctional contacts. Brain Res Dev Brain Res 1992;69:85-95.

34 Allt G, Lawrenson J: The blood-nerve barrier: enzymes, transporters and receptors - a comparison with the blood-brain barrier. Brain Res Bull 2000;52:1-12.

-35 Froehner S, Davies A, Baldwin S, Lienhard G: The blood-nerve barrier is rich in glucose transporter. J Neurocytol 1988;17:173-178.

- 36 Hawkins R, O’Kane R, Simpson I, Viña J: Structure of the blood-brain barrier and its role in the transport of amino acids. J Nutr 2006; 136:218S-226S.

- 37 Kanda T, Iwasaki T, Yamawaki M, Ikeda K: Isolation and culture of bovine endothelial cells of endoneurial origin. J Neurosci Res 1997;49:769-777.

- 38 Kido Y, Tamai I, Okamoto M, Suzuki F, Tsuji A: Functional clarification of MCT1-mediated transport of monocarboxylic acids at the blood-brain barrier using in vitro cultured cells and in vivo BUI studies. Pharm Res 2000; 17:55-62.

39 Michel M, Shinowara N, Rapoport S: Presence of a blood-nerve barrier within blood vessels of frog sciatic nerve. Brain Res 1984; 299:25-30.

40 Ohtsuki S, Tachikawa M, Takanaga H, Shimizu $\mathrm{H}$, Watanabe $\mathrm{M}$, Hosoya $\mathrm{K}$, Terasaki T: The blood-brain barrier creatine transporter is a major pathway for supplying creatine to the brain. J Cereb Blood Flow Metab 2002;22: 1327-1335.

41 Orte C, Lawrenson J, Finn T, Reid A, Allt G: A comparison of blood-brain barrier and blood-nerve barrier endothelial cell markers. Anat Embryol (Berl) 1999;199:509-517.

42 Poduslo J, Curran G, Berg C: Macromolecular permeability across the blood-nerve and blood-brain barriers. Proc Natl Acad Sci USA 1994;91:5705-5709.

43 Rechthand E, Smith Q, Rapoport S: Facilitated transport of glucose from blood into peripheral nerve. J Neurochem 1985;45:957964.

44 Saito T, Zhang Z, Ohtsubo T, Noda I, Shibamori Y, Yamamoto T, Saito H: Homozygous disruption of the mdrla P-glycoprotein gene affects blood-nerve barrier function in mice administered with neurotoxic drugs. Acta Otolaryngol 2001;121:735-742.

45 Sano Y, Shimizu F, Nakayama H, Abe M, Maeda T, Ohtsuki S, Terasaki T, Obinata M, Ueda M, Takahashi R, Kanda T: Endothelial cells constituting blood-nerve barrier have highly specialized characteristics as barrierforming cells. Cell Struct Funct 2007;32:139147.

46 Wadhwani K, Smith Q, Rapoport S: Facilitated transport of L-phenylalanine across bloodnerve barrier of rat peripheral nerve. Am J Physiol 1990;258:R1436-R1444.

47 Ohtsuki S, Terasaki T: Contribution of carrier-mediated transport systems to the bloodbrain barrier as a supporting and protecting interface for the brain; importance for CNS drug discovery and development. Pharm Res 2007;24:1745-1758.

-48 Gallo R, Dorschner R, Takashima S, Klagsbrun M, Eriksson E, Bernfield M: Endothelial cell surface alkaline phosphatase activity is induced by IL-6 released during wound repair. J Invest Dermatol 1997;109:597-603.

49 Latker C, Shinowara N, Miller J, Rapoport S: Differential localization of alkaline phosphatase in barrier tissues of the frog and rat nervous systems: a cytochemical and biochemical study. J Comp Neurol 1987;264:291-302.

50 Nakano Y, Beertsen W, van den Bos T, Kawamoto T, Oda K, Takano Y: Site-specific localization of two distinct phosphatases along the osteoblast plasma membrane: tissue non-specific alkaline phosphatase and plasma membrane calcium ATPase. Bone 2004;35:10771085.

$51 \mathrm{Ng} \mathrm{K}$, Schallenkemp J: Biochemical characteristics of a primary blood-brain barrier cell culture system as a function of the activity of the proteases used in tissue disaggregation. J Neurosci Methods 1996;68:49-53.

52 Muona P, Jaakkola S, Salonen V, Peltonen J: Expression of glucose transporter 1 in adult and developing human peripheral nerve. Diabetologia 1993;36:133-140.

53 Véga C, Poitry-Yamate C, Jirounek P, Tsacopoulos $\mathrm{M}$, Coles J: Lactate is released and taken up by isolated rabbit vagus nerve during aerobic metabolism. J Neurochem 1998;71: 330-337.

54 Kanai Y, Segawa H, Miyamoto K, Uchino H, Takeda E, Endou H: Expression cloning and characterization of a transporter for large neutral amino acids activated by the heavy chain of 4F2 antigen (CD98). J Biol Chem 1998;273:23629-23632.

55 Muruganandam A, Herx L, Monette R, Durkin J, Stanimirovic D: Development of immortalized human cerebromicrovascular endothelial cell line as an in vitro model of the human blood-brain barrier. FASEB J 1997;11: 1187-1197.

56 Pajic M, Norris MD, Cohn SL, Haber M: The role of the multidrug resistance-associated protein 1 gene in neuroblastoma biology and clinical outcome. Cancer Lett 2005;228:241246.

57 Deeley RG, Westlake C, Cole SP: Transmembrane transport of endo- and xenobiotics by mammalian ATP-binding cassette multidrug resistance proteins. Physiol Rev 2006;86:849899 .

58 Sharom FJ: The P-glycoprotein multidrug transporter. Essays Biochem 2011;50:161178.

-59 Hsiang B, Zhu Y, Wang Z, Wu Y, Sasseville V, Yang WP, Kirchgessner TG: A novel human hepatic organic anion transporting polypeptide (OATP2). Identification of a liver-specific human organic anion transporting polypeptide and identification of rat and human hydroxymethylglutaryl-CoA reductase inhibitor transporters. J Biol Chem 1999;274: 37161-37168.

60 Konig J, Cui Y, Nies AT, Keppler D: A novel human organic anion transporting polypeptide localized to the basolateral hepatocyte membrane. Am J Physiol Gastrointest Liver Physiol 2000;278:G156-G164.

61 Burckhardt G, Burckhardt BC: In vitro and in vivo evidence of the importance of organic anion transporters (OATs) in drug therapy. Handb Exp Pharmacol 2011;201:29-104.

- 62 VanWert AL, Gionfriddo MR, Sweet DH: Organic anion transporters: discovery, pharmacology, regulation and roles in pathophysiology. Biopharm Drug Dispos 2010;31: $1-71$.

63 Man S, Ubogu E, Ransohoff R: Inflammatory cell migration into the central nervous system: a few new twists on an old tale. Brain Pathol 2007;17:243-250.

64 Alon R, Ley K: Cells on the run: shear-regulated integrin activation in leukocyte rolling and arrest on endothelial cells. Curr Opin Cell Biol 2008;20:525-532.

65 Simon SI, Green CE: Molecular mechanics and dynamics of leukocyte recruitment during inflammation. Annu Rev Biomed Eng 2005;7:151-185. 
66 Greenwood J, Heasman SJ, Alvarez JI, Prat A, Lyck R, Engelhardt B: Review: leucocyte-endothelial cell crosstalk at the blood-brain barrier: a prerequisite for successful immune cell entry to the brain. Neuropathol Appl Neurobiol 2011;37:24-39.

-67 Yosef N, Ubogu EE: $\alpha(m) \beta(2)$-integrinintercellular adhesion molecule-1 interactions drive the flow-dependent trafficking of Guillain-Barré syndrome patient derived mononuclear leukocytes at the blood-nerve barrier in vitro. J Cell Physiol 2012;227:38573875.

68 Fina L, Molgaard H, Robertson D, Bradley N, Monaghan P, Delia D, Sutherland D, Baker M, Greaves M: Expression of the CD34 gene in vascular endothelial cells. Blood 1990;75: 2417-2426.

-69 Puri K, Finger E, Gaudernack G, Springer T: Sialomucin CD34 is the major L-selectin ligand in human tonsil high endothelial venules. J Cell Biol 1995;131:261-270.

70 Nourshargh S, Krombach F, Dejana E: The role of JAM-A and PECAM-1 in modulating leukocyte infiltration in inflamed and ischemic tissues. J Leukoc Biol 2006;80:714-718.

71 Newman PJ: The biology of PECAM-1. J Clin Invest 1997;99:3-8.

-72 Ubogu E, Cossoy M, Ransohoff R: The expression and function of chemokines involved in CNS inflammation. Trends Pharmacol Sci 2006;27:48-55.
73 Ubogu EE: Chemokine receptors as specific anti-inflammatory targets in peripheral nerves. Endocr Metab Immune Disord Drug Targets 2011;11:141-153.

74 Zlotnik A, Yoshie O: The chemokine superfamily revisited. Immunity 2012;36:705-716.

75 Hultström D, Malmgren L, Gilstring D, Olsson Y: FITC-dextrans as tracers for macromolecular movements in the nervous system. A freeze-drying method for dextrans of various molecular sizes injected into normal animals. Acta Neuropathol 1983;59:53-62.

76 Olsson Y: Studies on vascular permeability in peripheral nerves. I. Distribution of circulating fluorescent serum albumin in normal, crushed and sectioned rat sciatic nerve. Acta Neuropathol 1966;7:1-15.

77 Olsson Y: Topographical differences in the vascular permeability of the peripheral nervous system. Acta Neuropathol 1968;10:26-33.

78 Olsson Y: Studies on vascular permeability in peripheral nerves. IV. Distribution of intravenously injected protein tracers in the peripheral nervous system of various species. Acta Neuropathol 1971;17:114-126.

79 Abbott NJ, Rönnbäck L, Hansson E: Astrocyte-endothelial interactions at the bloodbrain barrier. Nat Rev Neurosci 2006;7:41-53.

80 Siddharthan V, Kim YV, Liu S, Kim KS: Human astrocytes/astrocyte-conditioned medium and shear stress enhance the barrier properties of human brain microvascular endothelial cells. Brain Res 2007;1147:39-50.

81 Jessen KR, Mirsky R: The origin and development of glial cells in peripheral nerves. Nat Rev Neurosci 2005;6:671-682.
82 Springer JE, Seeburger JL, He J, Gabrea A, Blankenhorn EP, Bergman LW: cDNA sequence and differential mRNA regulation of two forms of glial cell line-derived neurotrophic factor in Schwann cells and rat skeletal muscle. Exp Neurol 1995;131:47-52.

-83 Bar KJ, Saldanha GJ, Kennedy AJ, Facer P, Birch R, Carlstedt T, Anand P: GDNF and its receptor component Ret in injured human nerves and dorsal root ganglia. Neuroreport 1998;9:43-47.

84 Hammarberg H, Piehl F, Cullheim S, Fjell J, Hökfelt T, Fried K: GDNF mRNA in Schwann cells and DRG satellite cells after chronic sciatic nerve injury. Neuroreport 1996;7:857860.

85 Kanda T, Numata Y, Mizusawa H: Chronic inflammatory demyelinating polyneuropathy: decreased claudin-5 and relocated ZO-1. J Neurol Neurosurg Psychiatry 2004;75:765769.

86 Song L, Ge S, Pachter J: Caveolin-1 regulates expression of junction-associated proteins in brain microvascular endothelial cells. Blood 2007;109:1515-1523.

87 Cucullo L, Hossain M, Puvenna V, Marchi N, Janigro D: The role of shear stress in bloodbrain barrier endothelial physiology. BMC Neurosci 2011;12:40.

88 Rumbaut RE, Wang J, Huxley VH: Differential effects of L-NAME on rat venular hydraulic conductivity. Am J Physiol Heart Circ Physiol 2000;279:H2017-H2023. 